\title{
Impact of climate change on U.S. building energy demand: Financial implications for consumers and energy suppliers
}

\author{
Jianhua Huang $^{1 *}$, Kevin Robert Gurney $^{1,2}$ \\ 1. School of Life Sciences, Arizona State University, Tempe, AZ 85287 \\ 2. Julie Ann Wrigley Global Institute of Sustainability, Arizona State University, Tempe,
} AZ 85287

\section{Corresponding author:}

Jianhua Huang, School of Life Sciences, Arizona State University, Tempe, AZ 85281; jianhua.huang.1@asu.edu

\section{Keywords}

Climate change impacts; energy impacts; sustainable energy; cost/benefit analysis; energy demands and supply; financial implication

\begin{abstract}
Based on the impacts of climate change on U.S. building energy consumption, we quantify the financial implications to consumers and suppliers at finer space (state) and time (monthly) scales than previously reported. For the U.S. as a whole, we find building energy costs decrease by $\sim 7$ billion $\$$ year in the residential sector, while costs increase by $~ 2.2$ billion $\$ /$ year in the commercial sector. For cold-weather states (e.g., Vermont), there are residential energy savings of up to $340 \$$ year, while warmer states (e.g., Florida) see increased residential energy costs of up to 231 \$year per household. The increased summertime cooling demand poses important
\end{abstract}


questions for the electricity supply system. Electricity reserve margins fall below $10 \%$ in all North American Electric Reliability Corporation (NERC) regions by the end of this century. In order to maintain a reliable electricity supply, an additional 80.6 gigawatt $(\mathrm{GW})$ of capacity is needed, which we estimate to cost between 19.2 and 72.1 billion \$/year for construction and operation. These estimates are also sensitive to changes in population distribution. Compared to a 2010 population distribution, results based on a 2090 population distribution show reduced savings nationally.

\section{Introduction}

Energy consumption in residential and commercial buildings will be directly impacted by climate change through the need for space cooling and heating. Buildings account for more than $40 \%$ of 2010 U.S. primary energy consumption, of which $23 \%$ was used for space heating and $15 \%$ was used for space cooling (Kelso 2012). A number of studies have assessed the impacts of climate change on building energy consumption within the U.S.. Some of these studies estimated impacts based on historical relationships between climate variables and energy consumption (Sailor and Muñoz 1997, Sailor et al 1998, Sailor 2001, Ruth and Lin 2006, Hamlet et al 2010, Sathaye et al 2013). Others evaluated the impact with energy simulation models, either at the building scale (Scott et al 1994, Xu et al 2012, Huang 2006, Wang and Chen 2014, Dirks et al 2015, Huang and Gurney 2016b) or the regional/international scale (Zhou et al 2013, 2014, Isaac and Van Vuuren 2009, Hadley et al 2006, McFarland et al 2015). In general, these studies found a net energy consumption increase in the warmer regions of the U.S. due to increased cooling demand. In colder regions, they found a net energy consumption decrease due to lower heating demand. When integrated over the whole nation, however, study results varied from a net 
increase to a net decrease in building energy consumption and were dependent upon the research methods, the future time period examined, the emissions scenario used, and the energy form (onsite or source energy) chosen.

There has been little systematic translation of these energy demand changes into the financial cost to both building energy consumers and suppliers. The few studies that have attempted such an assessment have estimated the financial impacts of climate change to the U.S. energy sector based on national/international economic modeling (Linder and Inglis 1989, Hadley et al 2006, Rosenthal et al 1995, Mansur et al 2008, Mendelsohn et al 2000, Jaglom et al 2014). Some studies found increased costs in the energy sector, ranging from a few billion dollars to a few hundred billion dollars (Linder and Inglis 1989, Hadley et al 2006, Mansur et al 2008, Jaglom et al 2014). By contrast, other studies found a savings of a few billion dollars in energy expenditures (Rosenthal et al 1995, Mendelsohn et al 2000). However, as with the underlying energy demand impact analysis, past analysis of the financial impact has overlooked the importance of climate variation and extremes at finer space and time scales where the financial implications are most acute and where action will likely be needed to plan effectively for an altered energy consumption future.

In a recent paper, Huang and Gurney (2016a) explored the sensitivity of the relationship between climate change and building energy consumption in the U.S. by testing the impact of three important analytical elements: the spatiotemporal resolution of analysis, the balance point temperature method used, and changes in future population distribution. In this earlier study, we used empirically-based balance point temperatures and empirically-based relationships between energy consumption and temperature over the 2008-2012 time period for each state. We then 
predicted the monthly energy consumption in future time periods (2020-2099) driven by the 20 different climate models used in phase 5 of the Coupled Model Intercomparison Project (CMIP5) (van Vuuren et al 2011). The daily temperature over the 2006-2099 time period under the Representative Concentration Pathways (RCP) 8.5 emission scenario (radiative forcing rises to $8.5 \mathrm{~W} / \mathrm{m} 2$ in 2100) was used to predict future energy consumption. We selected the RCP 8.5 scenario, because it was simulated by most CMIP5 climate models, and it represents the worstcase scenario (most dramatic temperature change) for which electricity supply and demand must prepare. Finally, we also analyzed the sensitivity of cost differences to the change of population distribution in 2090 .

Using this ensemble of 20 climate model outputs, we found that the summer electricity demand increased by more than 50\% and the winter non-electric (natural gas, propane, distillate fuel oil, kerosene, and wood) demand decreased by up to $48 \%$ in some states by the end of this century. These opposing extremes canceled when examined at the national/annual scale, ending up with energy demand changes approaching zero in all future time periods. In contrast to most past studies, which estimated the impact of climate change on energy consumption at the national/annual scale, we explored the implications of climate change at the state and seasonal scales. Furthermore, instead of using the traditional fixed $18.3{ }^{\circ} \mathrm{C}\left(65^{\circ} \mathrm{F}\right)$ balance point temperature, we developed an empirically-based state-specific balance point temperature, which improved model performance in all states and provided more reliable estimates of future energy consumption. Finally, we found that projected population redistribution exacerbates the building energy consumption impacts of climate change, intensifying the state-scale increases and decreases. When we examined the impact of climate change with the current population 
distribution, we found a net decrease in national energy consumption. Allowing for a changed future population distribution, we found a net increase in national energy consumption.

This study quantifies the financial implications of these changes to energy consumers and suppliers, and examines the sensitivity of these implications to population distribution. To do this, we use current consumer energy prices and electricity capacity reserve requirements and quantify the impact on the residential and commercial sector separately. We quantify the additional electricity capacity required to satisfy the reserve margin requirement for each North American Electric Reliability Corporation (NERC) region, further converted to annual costs based on construction and operating costs. These estimates are compared to the same analysis performed at the U.S.-aggregate scale to further highlight the improved accuracy and relevance of the subnational analysis. Finally, we compare the financial impacts based on a 2010 versus a projected 2090 population distributions, to highlight the importance of the spatial relationship between people, energy consumption, and climate change.

We do not attempt to comprehensively project all of the variables that are likely to determine future energy supply and demand costs to consumers from the impact of climate change (e.g., energy price, energy mix, energy policy, building technology). We consider many of these variables difficult to predict over long timeframes and attempting to do so would potentially mask the impact of the variables of interest here - the space/time covariation of climate change, energy demand and population distribution. Thus, it is more appropriate to interpret the results of this study as a ceteris paribus analysis.

\section{Methodology}

\subsection{Consumer energy cost}


The Department of Energy/Energy Information Administration's State Energy Data System (EIA SEDS) provides state-scale end-use energy consumption (mmBtu) and end-user energy prices ( $\$ / \mathrm{mmBtu}$ ) by fuel type, state, and sector (U.S. Energy Information Administration). The electricity price ( $\$ / \mathrm{mmBtu})$ is calculated as the average of 2008-12 electricity prices weighted by annual end-use electricity consumption (Table 1). Similarly, the non-electric energy price is calculated as the average of 2008-12 non-electric fuel prices weighted by annual end-use consumption of each non-electric fuel. These state-specific per unit energy prices are used to estimate the state residential and commercial building energy expenditures given the altered energy consumption under climate change.

Table 1. Electricity and non-electric consumer energy prices (2008-2012 average) and annual cost difference between 2080-99 and 2008-12 for the residential and commercial sectors. Currency in 2008-2012 U.S. dollars (\$).

\begin{tabular}{|c|c|c|c|c|c|c|c|}
\hline \multirow[t]{2}{*}{ State } & \multicolumn{2}{|c|}{$\begin{array}{l}\text { Electricity price } \\
(\$ / \mathrm{mmBtu})\end{array}$} & \multicolumn{2}{|c|}{$\begin{array}{l}\text { Non-electric price } \\
(\$ / m m B t u)\end{array}$} & \multicolumn{3}{|c|}{ Cost difference (million \$) } \\
\hline & Residential & Commercial & Residential & Commercial & Residential & Commercial & Total \\
\hline $\mathrm{AL}$ & 31.76 & 30.01 & 16.44 & 15.11 & 80 & 53 & 133 \\
\hline AZ & 31.85 & 27.41 & 16.86 & 12.83 & 164 & 143 & 307 \\
\hline AR & 26.70 & 22.09 & 12.63 & 10.20 & 10 & -29 & -19 \\
\hline $\mathrm{CA}$ & 43.02 & 38.39 & 10.91 & 9.75 & -703 & 522 & -181 \\
\hline $\mathrm{CO}$ & 31.62 & 26.19 & 9.57 & 9.00 & -251 & -14 & -265 \\
\hline CT & 55.43 & 47.33 & 20.17 & 12.98 & -205 & 109 & -96 \\
\hline $\mathrm{DE}$ & 40.49 & 32.93 & 18.66 & 14.83 & -18 & -1 & -19 \\
\hline DC & 38.85 & 37.86 & 14.18 & 12.74 & -33 & 18 & -15 \\
\hline FL & 34.23 & 29.42 & 18.04 & 14.04 & 1649 & 1062 & 2711 \\
\hline GA & 30.66 & 27.26 & 15.97 & 12.38 & -207 & 85 & -122 \\
\hline ID & 23.02 & 18.82 & 11.01 & 10.42 & -94 & -50 & -144 \\
\hline IL & 33.43 & 27.16 & 9.99 & 9.39 & -565 & 19 & -546 \\
\hline IN & 28.43 & 24.86 & 11.19 & 9.62 & -175 & -16 & -191 \\
\hline IA & 30.01 & 22.57 & 12.05 & 9.41 & -175 & -73 & -248 \\
\hline KS & 29.55 & 24.37 & 11.62 & 10.60 & -172 & -8 & -180 \\
\hline KY & 25.48 & 23.43 & 11.92 & 10.41 & -24 & 26 & 2 \\
\hline LA & 26.18 & 24.89 & 12.94 & 11.91 & 177 & 137 & 314 \\
\hline ME & 45.47 & 36.27 & 19.86 & 18.79 & -102 & -39 & -141 \\
\hline MD & 40.64 & 34.10 & 15.34 & 11.81 & -133 & 54 & -79 \\
\hline MA & 46.04 & 43.58 & 17.99 & 14.17 & -513 & 71 & -442 \\
\hline MI & 36.50 & 29.03 & 11.93 & 9.67 & -687 & 15 & -672 \\
\hline MN & 30.88 & 24.41 & 10.74 & 8.87 & -296 & -111 & -407 \\
\hline MS & 29.83 & 27.91 & 13.29 & 11.56 & 53 & 40 & 93 \\
\hline MO & 26.69 & 21.87 & 12.10 & 11.05 & -287 & -64 & -351 \\
\hline MT & 27.59 & 25.60 & 12.18 & 9.75 & -111 & -58 & -169 \\
\hline $\mathrm{NE}$ & 26.20 & 22.27 & 10.86 & 8.07 & -106 & -44 & -150 \\
\hline NV & 35.51 & 28.35 & 12.57 & 10.12 & -16 & -8 & -24 \\
\hline
\end{tabular}




\begin{tabular}{lll|ll|lll}
\hline NH & 47.40 & 41.34 & 19.75 & 16.74 & -83 & 9 & -74 \\
NJ & 47.23 & 40.14 & 14.45 & 10.81 & -316 & 161 & -155 \\
NM & 31.06 & 25.83 & 11.31 & 8.85 & -104 & -37 & -141 \\
NY & 53.01 & 46.63 & 16.69 & 12.21 & -1204 & 391 & -813 \\
NC & 29.76 & 23.73 & 15.76 & 12.85 & -67 & 27 & -40 \\
ND & 23.98 & 21.44 & 13.12 & 11.42 & -62 & -46 & -108 \\
OH & 32.38 & 27.96 & 12.23 & 10.28 & -520 & -33 & -553 \\
OK & 26.82 & 21.69 & 11.61 & 10.71 & -95 & -37 & -132 \\
OR & 26.58 & 22.75 & 12.15 & 10.95 & -113 & -27 & -140 \\
PA & 36.19 & 28.42 & 16.49 & 12.80 & -1125 & -284 & -1409 \\
RI & 45.52 & 38.92 & 19.72 & 15.84 & -118 & 5 & -113 \\
SC & 31.42 & 26.36 & 15.40 & 12.64 & 60 & 30 & 90 \\
SD & 26.48 & 22.02 & 12.29 & 9.64 & -54 & -26 & -80 \\
TN & 27.85 & 28.76 & 12.27 & 11.11 & 116 & 96 & 212 \\
TX & 34.53 & 27.16 & 12.08 & 9.69 & 871 & 622 & 1493 \\
UT & 26.02 & 21.23 & 8.71 & 8.37 & -120 & -38 & -158 \\
VT & 45.83 & 39.36 & 19.64 & 18.26 & -87 & -19 & -106 \\
VA & 30.70 & 22.90 & 14.98 & 11.63 & -196 & -14 & -210 \\
WA & 23.47 & 21.24 & 13.13 & 11.91 & -541 & -314 & -855 \\
WV & 25.18 & 21.74 & 10.85 & 10.77 & -67 & -46 & -113 \\
WI & 36.54 & 29.17 & 11.65 & 9.53 & -263 & -21 & -284 \\
WY & 26.10 & 21.88 & 11.60 & 10.27 & -59 & -45 & -104 \\
U.S. total & 33.79 & 29.76 & 13.40 & 11.04 & -6889 & 2193 & -4696 \\
\hline
\end{tabular}

The per household annual energy consumption cost difference between the future and current periods (due to climate change) is calculated for the residential sector in each state as follows:

$\mathrm{CD}=\left(\mathrm{P}_{\text {ele }} \times \mathrm{SD}_{\text {ele }}+\mathrm{P}_{\text {nele }} \times \mathrm{SD}_{\text {nele }}\right) / \mathrm{HH}$

where the cost difference per household, $C D$, is a function of the price, $P,(\$ / \mathrm{mmBtu})$ for electricity, ele, and non-electric fuel, nele, the on-site energy difference, $S D,(\mathrm{mmBtu})$, and the number of households (U.S. Census Bureau), $H H$. The product of $P_{\text {ele }}$ and $S D_{\text {ele }}$ represents the change in state total electricity consumption costs, while the product of $P_{\text {nele }}$ and $S D_{\text {nele }}$ represents the change in non-electricity consumption costs. The sum of these two terms, divided by the number of households in a state, represents the change of total energy consumption cost per household. 
Because there is a general trend towards electricity demand increases and non-electric demand decreases in the future (Zhou et al 2013, 2014, Isaac and Van Vuuren 2009, Hadley et al 2006, McFarland et al 2015, Huang and Gurney 2016a, Huang and Gurney 2016b), a high price ratio of electricity to non-electric fuel will generally lead to higher future consumer expenditures. The price ratios of electricity to non-electric fuel are calculated for state residential and commercial sectors separately, which are used to explore the cost difference patterns in the two sectors.

\subsection{Electricity generation capacity and cost}

High electricity demand typically occurs during summer months and Huang and Gurney (2016) show that summer electricity consumption will increase more than $20 \%$ in some states by the end of the century. As a result, additional electricity generation capacity will likely be required to meet the increased electricity demand. The North American Electric Reliability Corporation (NERC) is a nonprofit organization tasked with maintaining reliable electricity supply for the North America. There are eight NERC regions within the contiguous United States: Florida Reliability Coordinating Council (FRCC), Midwest Reliability Organization (MRO), Northeast Power Coordinating Council (NPCC), ReliabilityFirst Corporation (RFC), SERC Reliability Corporation (SERC), Southwest Power Pool, RE (SPP), Texas Reliability Entity (TRE), and Western Electricity Coordinating Council (WECC) (North American Electric Reliability Corporation) . The electricity generated in one region is primarily supplied to energy consumers in the same region; the inter-region electricity trade is small and limited by the available transmission lines (North American Electric Reliability Corporation). NERC publishes the estimated summer electricity demand, generation capacity, and reserve margin for each assessment area annually. The reserve margin is defined as the difference between generation capacity and electricity demand, divided by the electricity demand. NERC recommends a 15\% 
reserve margin to maintain electricity system (North American Electric Reliability Corporation). In the 2008-2010 assessment reports, each assessment area belongs to one NERC region. Starting in 2011, the assessment areas were redistricted, with some assessment areas overlapping multiple NERC regions. This makes it impossible to attribute each assessment area to one NERC region and calculate the NERC level reserve margin. As a result, we only use the 2008-2010 assessment reports to calculate the average electricity demand, generation capacity, and reserve margin for each NERC region in the current period. In future periods, because electricity demand is estimated at the state scale and state boundaries do not coincide with the NERC boundaries, we downscale the state-scale electricity demand to the county level by population and assign each county a NERC region. Most counties are assigned NERC regions based on the Emissions \& Generation Resource Integrated Database (eGRID) (U.S. Environmental Protection Agency). If a county is missing from eGRID, it is assigned to the NERC region according to the affiliation of its closest neighbors (majority affiliation). We have compared the results achieved from choosing a different number of neighbors in this calculation (e.g., 1, 3, 5, and 7), and the NERC borders are most well-defined and reasonable when three neighbors are used. The county scale summer electricity demand is then aggregated to the NERC regions in order to calculate the reserve margin for each NERC region in future periods. The future energy demand and reserve margin are further used to calculate the additional generation capacity needed to satisfy the $15 \%$ reserve margin requirement.

The Levelized Cost Of Electricity (LCOE) is usually used to estimate the cost of per unit electricity generated (\$/MWh) associated with constructing and operating a new power plant during its whole life cycle (U.S. Energy Information Administration). LCOE consists of fixed costs (including capital cost, fixed operation \& management cost, transmission investment, and 
subsidy), and variable operation \& management (VOM) costs that depend on electricity generation. The cost for building and operating additional capacity is therefore calculated as follows:

$T C=G C * F C * 8760 * C F+G C * V C * O H$

where $G C$ represents the additional generation capacity (MW) required, $F C$ represents the per unit fixed cost (\$/MWh), $V C$ represents the per unit VOM cost $(\$ / \mathrm{MWh}), C F$ represents the capacity factor (\%), $\mathrm{OH}$ represents the operational hours, and $T C$ is the annual total cost $(\$)$. The fixed cost, VOM cost, and capacity factor are extracted from the LCOE provided by the U.S. Energy Information Administration (Table 3). On the right hand side of the equation, the first element $(G C * F C * 8760 * C F)$ represents the total fixed cost for the additional generation capacity in one year (8760 hours), while the second element $(G C * V C * O H)$ represents the total VOM cost during operating hours. We assume the additional generation capacity is operating full time during the summer months (2190 hours) to satisfy the increased electricity demand.

Because population is used to weight the energy consumption difference, the sensitivity of cost and reserve margin changes to population is also evaluated using the 2090 population extracted from the Integrated Climate and Land Use Scenarios (ICLUS) dataset (U.S. Environmental Protection Agency 2010). The ICLUS dataset provides a county-scale population projection used for different emission scenarios. To be consistent with the high-emission scenario used here, the 2090 population distribution under the ICLUS high-emission scenario is used. In order to exclude the effect of total population change, the 2090 national population is held constant at the 2010 U.S. total value. As a result, only the changes in population distribution are reflected in our results. 


\section{Results and Discussion}

\subsection{Impact on energy consumers}

The spatiotemporal changes in building energy demand have important financial and strategic implications for building energy consumers. In 2080-99, all else being equal, the residential and commercial sectors in the warmer states would see increases in annual energy costs (Table 1). For example, using current consumer energy prices, the annual building energy costs in Florida would increase $\$ 2.7$ billion ( $\$ 1.6$ billion increase in the residential sector and $\$ 1.1$ billion increase in the commercial sector). By contrast, consumers in colder states would see energy cost declines. For example, the state of Pennsylvania would see a savings of $\$ 1.4$ billion ( $\$ 1.1$ billion savings in the residential sector and $\$ 284$ million savings in the commercial sectors) in annual building energy costs. For the U.S. economy as a whole, the residential sector would experience a net energy savings of 6.9 billion \$/year while the commercial building sector would see energy costs rise 2.1 billion \$/year. Across the two sectors this would amount to a net savings of 4.7 billion $\$$ year.

The residential energy cost difference can be represented at the mean household scale within each state. Figure 1 shows the annual state mean residential household energy cost difference change between the 2080-99 time period and the current time period. The consumers in the warmer states would see an energy cost increase, while the consumers in the colder states would see an energy cost decline. The annual household energy cost differences range from -\$340/household (savings) in Vermont to $+\$ 231 /$ household in Florida (cost increase). 


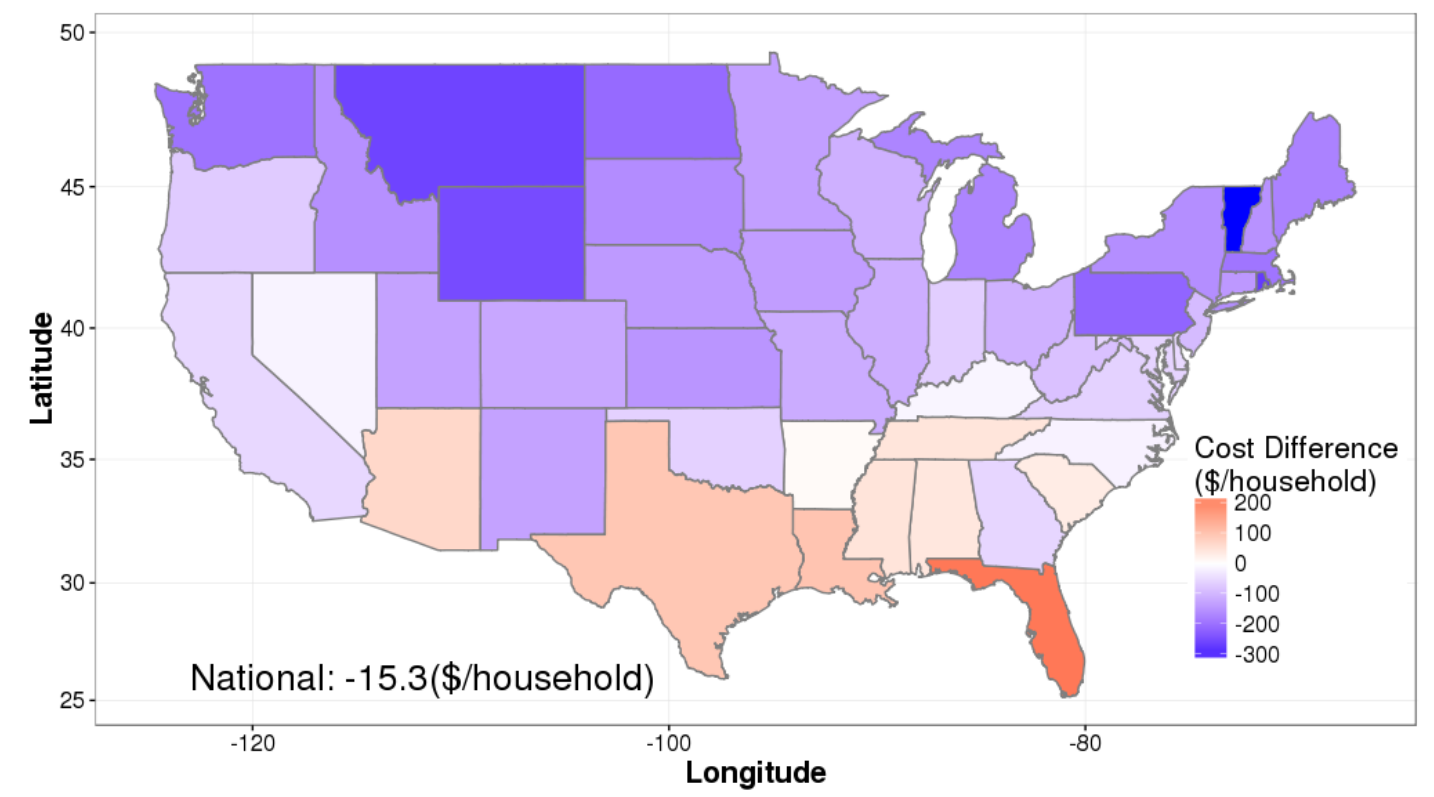

Figure 1. Annual average state-scale residential household energy cost difference ( $\$ /$ household) between the 2080-99 time period and 2008-2012.

Figure 2 shows the price ratios of electricity/non-electric fuels for each state. In the colder states, the ratio of electricity to non-electric fuel price is typically large, but the total site energy change is dominated by the decline in non-electric fuel needs. As a result, the greater electricity price is more than offset by the non-electric fuel demand decline, resulting in net savings. In the warmer states, the ratio of electricity to non-electric fuel price is usually small (Figure 2). Although these states show greater increases in electricity demand, the low price ratios mean that the increased electricity cost does not overwhelm the non-electric fuel savings. The high price ratios of electricity/non-electric fuels in the colder states and the low price ratios in warmer states result in a net savings for the whole U.S.. Because the price ratio in the commercial sector is usually larger than the residential sector, and commercial buildings typically use less non-electric fuel for heating after business hours, there is a net increase in commercial sector building energy cost but a net savings in the residential sector building energy cost when integrated across the United States. 


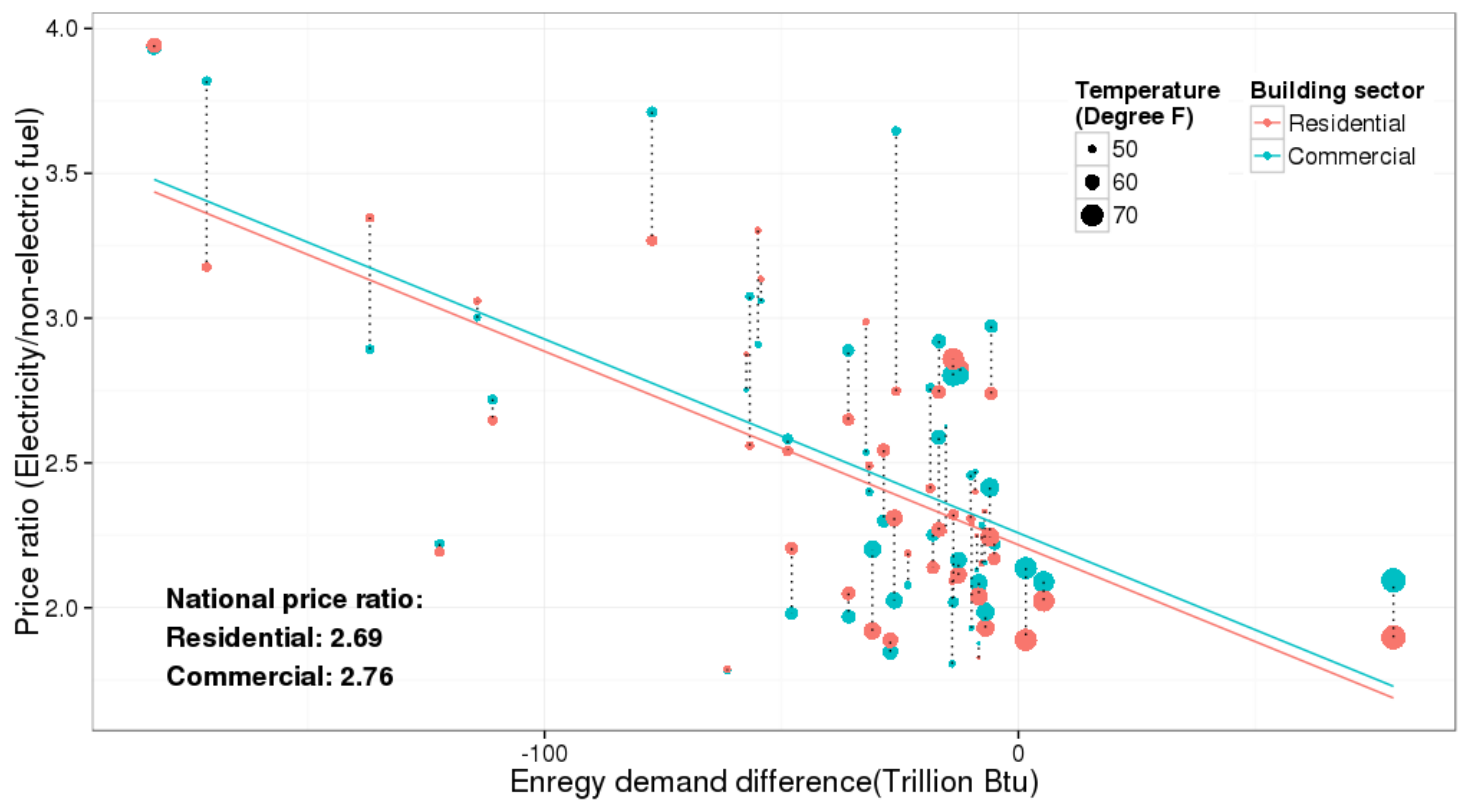

Figure 2. Relationship between the price ratio (Electricity price/non-electric fuel price) and the site energy difference (2080-99 minus 2008-2012). Symbol size represents the annual average temperature in 2008-2012. Each symbol represents one state. The national price ratio is the mean value of all states weighted by the state population.

\subsection{Impacts on energy suppliers}

Energy supply capacity must also consider the physical and financial implications of altered future building energy needs in spatiotemporal detail. In the current period (2008-2012), all NERC regions have reserve margins sufficient (>15\%) to maintain the reliability of electricity supply during summer (Figure 3). The current reserve margins range from $16.7 \%$ in TRE to $26.2 \%$ in WECC, with reserve margins in most NERC regions greater than $20 \%$. 


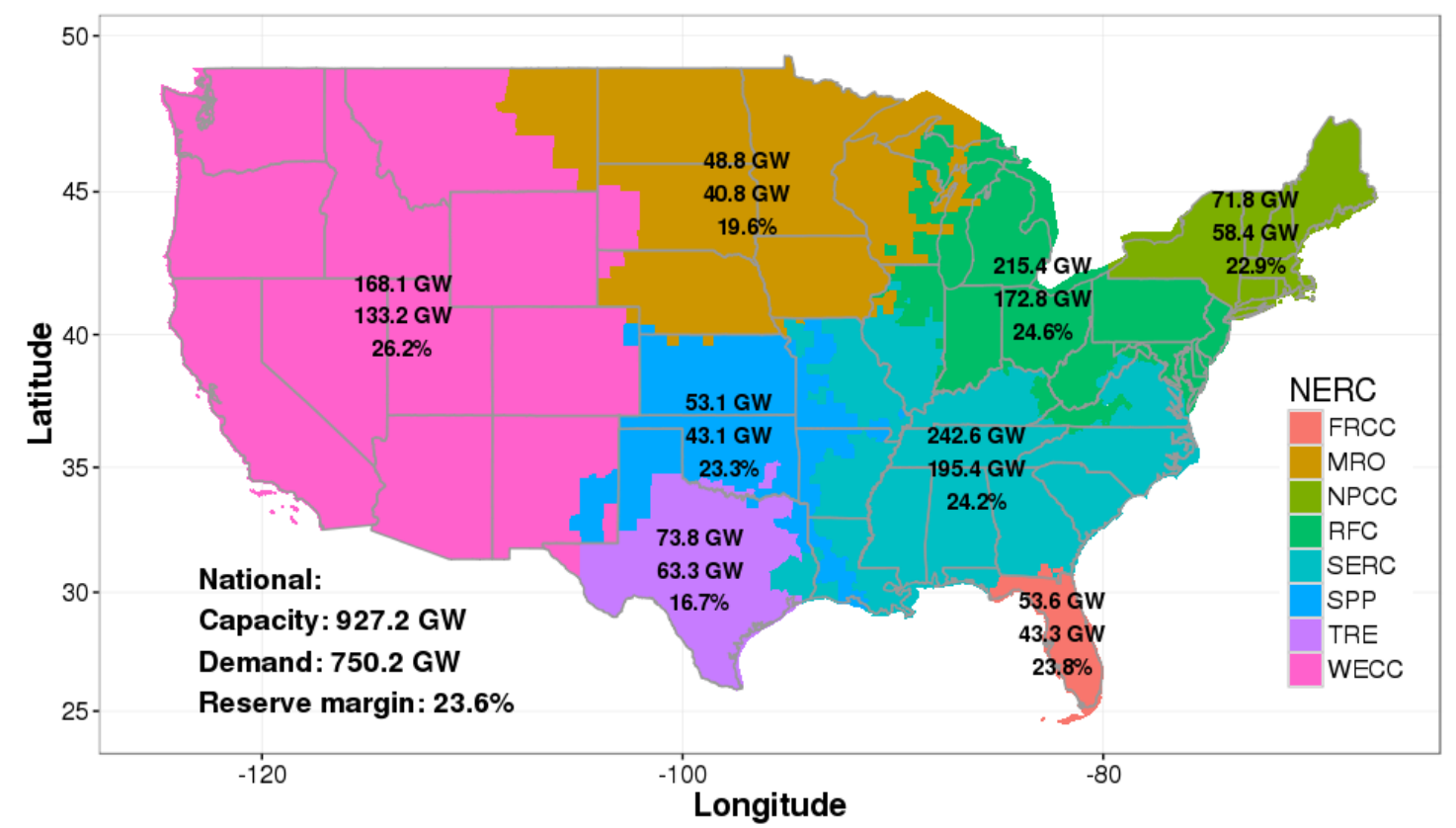

Figure 3. NERC region electricity generation capacity, electricity demand, and reserve margin during the 2008-12 summer. The top, middle, and bottom numbers in each NERC region represent generation capacity $(\mathrm{GW})$, electricity demand $(\mathrm{GW})$, and reserve margin $(\%)$, respectively.

Under the estimated building electricity demand increases, summer regional reserve margins fall below $15 \%$ in different future time periods for different NERC regions (Table 2), with the NPCC passing this threshold first (2020-39). By the end of this century, the reserve margins in all of the eight NERC regions fall below $10 \%$ during the summer season, with the smallest $(-2.9 \%)$ reserve margin in the NPCC region. For the U.S. as a whole, the reserve margin passes the $15 \%$ threshold in $2060-79$, and it reaches $5.9 \%$ by the end of this century. In order to maintain the $15 \%$ reserve margin, $80.6 \mathrm{GW}$ of additional capacity would be needed for the whole U.S. in the period of 2080-99, with the greatest capacity need in the RFC region (23.2GW). The RFC region requires the greatest amount of additional capacity, because this area covers a large population. What is more, the relative energy demand changes in the northern areas are usually higher than the southern area during summer (Huang and Gurney 2016a). 
Table 2. Electricity supply capacity reserve margin (\%) in future periods, and additional capacity (GW, within parenthesis) required to meet the $15 \%$ requirement.

\begin{tabular}{lllll}
\hline NERC & $\mathbf{2 0 2 0 - 3 9}$ & $\mathbf{2 0 4 0 - 5 9}$ & $\mathbf{2 0 6 0 - 7 9}$ & $\mathbf{2 0 8 0 - 9 9}$ \\
\hline FRCC & 22.1 & 17 & $11(1.9)$ & $5.1(5.1)$ \\
MRO & 16.5 & $12.5(1.1)$ & $8.6(2.9)$ & $5(4.6)$ \\
NPCC & $13.9(0.7)$ & $8.1(4.6)$ & $2.1(9.1)$ & $-2.9(13.2)$ \\
RFC & 18.9 & $13.7(2.5)$ & $8.5(12.9)$ & $3.8(23.2)$ \\
SERC & 22.5 & 18 & $13.1(4.1)$ & $7.8(16.1)$ \\
SPP & 23.1 & 19.1 & $14.6(0.2)$ & $9.6(2.6)$ \\
TRE & 17.9 & $13.8(0.8)$ & $9.5(3.7)$ & $4.3(7.6)$ \\
WECC & 23.4 & 18.8 & $14.3(1.1)$ & $9.6(8.2)$ \\
U.S. Total & $20.5(0.7)$ & $15.7(9)$ & $10.8(35.9)$ & $5.9(80.6)$ \\
\hline
\end{tabular}

The Levelized Cost of Electricity (LCOE) is used to estimate the cost of building and operating additional U.S. electricity grid capacity. Using contemporary estimates of the LCOE, an additional capacity of $80.6 \mathrm{GW}$ would constitute a fixed cost ranging from 7.1 billion \$/year to 65.3 billion \$/year (Table 3). If this new capacity is used for electricity generation during the summer and VOM cost is considered for those times, the total cost would range from 19.2 billion \$/year to 72.1 billion \$/year. Natural gas-fired power plants (e.g., conventional combined cycle, advanced combined cycle, and advanced combustion turbine) are the most plausible plant types to satisfy the increased summer electricity demand, given that they are reliable, consistent, and can be operated at relatively low cost. Although some non-dispatchable plant types (e.g., wind and solar photovoltaic) also show low total costs, their energy sources are intermittent and it is less likely that these technologies will be used to supply electricity during the whole summer season. However, it is worth mentioning that some U.S. power supply has recently switched to renewable energy sources (e.g., wind and solar). Compared to 2015, it is expected that renewables electricity generation will double by 2030 and increase $150 \%$ by 2040 (U.S. Energy Information Administration 2016). In areas with a larger share of renewable energy supply, the 
renewables-based power plants can satisfy part of the increased electricity consumption at relatively low costs (Nastasi and Basso 2016).

Even with the cheapest option ( $\$ 19.2$ billion), the estimated annual cost of adding and operating 80.6 GW of electricity capacity is substantially higher than the annual consumer savings noted above. Hence, it is possible that the ultimate cost of building additional power plants may be passed to electricity consumers. As a result, some states for which the net building energy demand changes resulted in savings, may end up with a net increase after accounting for the added capacity costs. The estimation of how energy supply and new facility costs are passed to consumers could be achieved with more sophisticated economic supply/demand modeling but that was considered beyond the scope of this study.

Table 3. The Levelized Cost Of Electricity (LCOE) for new electricity generation capacity in the U.S. (2012 \$/MWh) (U.S. Energy Information Administration).

\begin{tabular}{|c|c|c|c|c|c|}
\hline Plant type $^{1}$ & $\begin{array}{r}\text { Capacity } \\
\text { factor }(\%)\end{array}$ & $\begin{array}{l}\text { Fixed cost } \\
(\$ / \mathrm{MWh})\end{array}$ & $\begin{array}{l}\text { VOM cost } \\
\text { (\$/MWh) }\end{array}$ & $\begin{array}{l}\text { Fixed cost for } 80.6 \mathrm{GW} \\
\text { (billion } \$ / \text { year) }\end{array}$ & $\begin{array}{l}\text { Total cost for } 80.6 \mathrm{GW}^{2} \\
\text { (billion } \$ / \text { year) }\end{array}$ \\
\hline \multicolumn{6}{|l|}{ Dispatchable } \\
\hline Conventional Coal & 85 & 65.4 & 30.3 & 39.2 & 44.6 \\
\hline IGCC & 85 & 84.2 & 31.7 & 50.5 & 56.1 \\
\hline IGCC with CCS & 85 & 108.8 & 38.6 & 65.3 & 72.1 \\
\hline \multicolumn{6}{|l|}{ Natural Gas-Fired } \\
\hline Conventional CC & 87 & 17.2 & 49.1 & 10.6 & 19.2 \\
\hline Advanced CC & 87 & 18.9 & 45.5 & 11.6 & 19.6 \\
\hline Advanced CC with CCS & 87 & 35.7 & 55.6 & 21.9 & 31.7 \\
\hline Conventional CT & 30 & 46.4 & 82 & 9.8 & 24.3 \\
\hline Advanced $C T$ & 30 & 33.4 & 70.3 & 7.1 & 19.5 \\
\hline Advanced Nuclear & 90 & 74.3 & 11.8 & 47.2 & 49.3 \\
\hline Geothermal & 92 & 44.4 & 0 & 28.8 & 28.8 \\
\hline Biomass & 83 & 63.1 & 39.5 & 37.0 & 44.0 \\
\hline \multicolumn{6}{|l|}{ Non-dispatchable } \\
\hline Wind & 35 & 80.3 & 0 & 19.8 & 19.8 \\
\hline Wind-Offshore & 37 & 204 & 0 & 53.3 & 53.3 \\
\hline
\end{tabular}




\begin{tabular}{lccccc} 
Solar PV & 25 & 118.5 & 0 & 20.9 & 20.9 \\
Solar Thermal & 20 & 223.6 & 0 & 31.6 & 31.6 \\
Hydro & 53 & 78.1 & 6.4 & 29.2 & 30.4 \\
\hline
\end{tabular}

${ }^{1}$ Abbreviation for plant type: CC — Combined Cycle, IGCC - Integrated Coal-Gasification Combined Cycle, CCS Carbon Control and Sequence, CT-Combustion Turbine

${ }^{2}$ Total cost assumes that the $80.6 \mathrm{GW}$ capacity is used for generation during the summer only $(\mathrm{OH}=2190$ hours)

\subsection{Sensitivity to population distribution}

The population projection used here show population shifting from inland/colder areas to coastal/warmer areas by the end of this century (U.S. Environmental Protection Agency 2010). This spatial redistribution of population lessens the impacts of climate change in the colder areas, while exacerbating impacts in the warmer areas. Based on the 2090 population distribution, the estimated costs imposed by climate change are further increased in most states compared to the 2010 population distribution results (Figure 4a). For example, based on the 2090 population distribution, the costs increase from $+\$ 2.7$ billion to $+\$ 3.9$ billion in Florida, an extra $\$ 1.2$ billion. As a result of these higher costs in most states, the national savings found with the 2010 population distribution is reduced by $\$ 3.4$ billion (from $-\$ 4.7$ to $-\$ 1.3$ billion) when the 2090 population distribution is used.

The reserve margins are also impacted by the future changes in population distribution (Figure 4b). Generally, the reserve margin in the southern and western regions is further reduced due to the increased population, while the reserve margin in the northern regions increases due to the population declines. Compared to the results based on the 2010 population, the reserve margin based on the 2090 population is reduced by 7 percentage points in the FRCC region, while it is increased by 3.8 percentage points in the MRO region. At the national scale, these large changes cancel each other, resulting in slightly larger reserve margin values. 

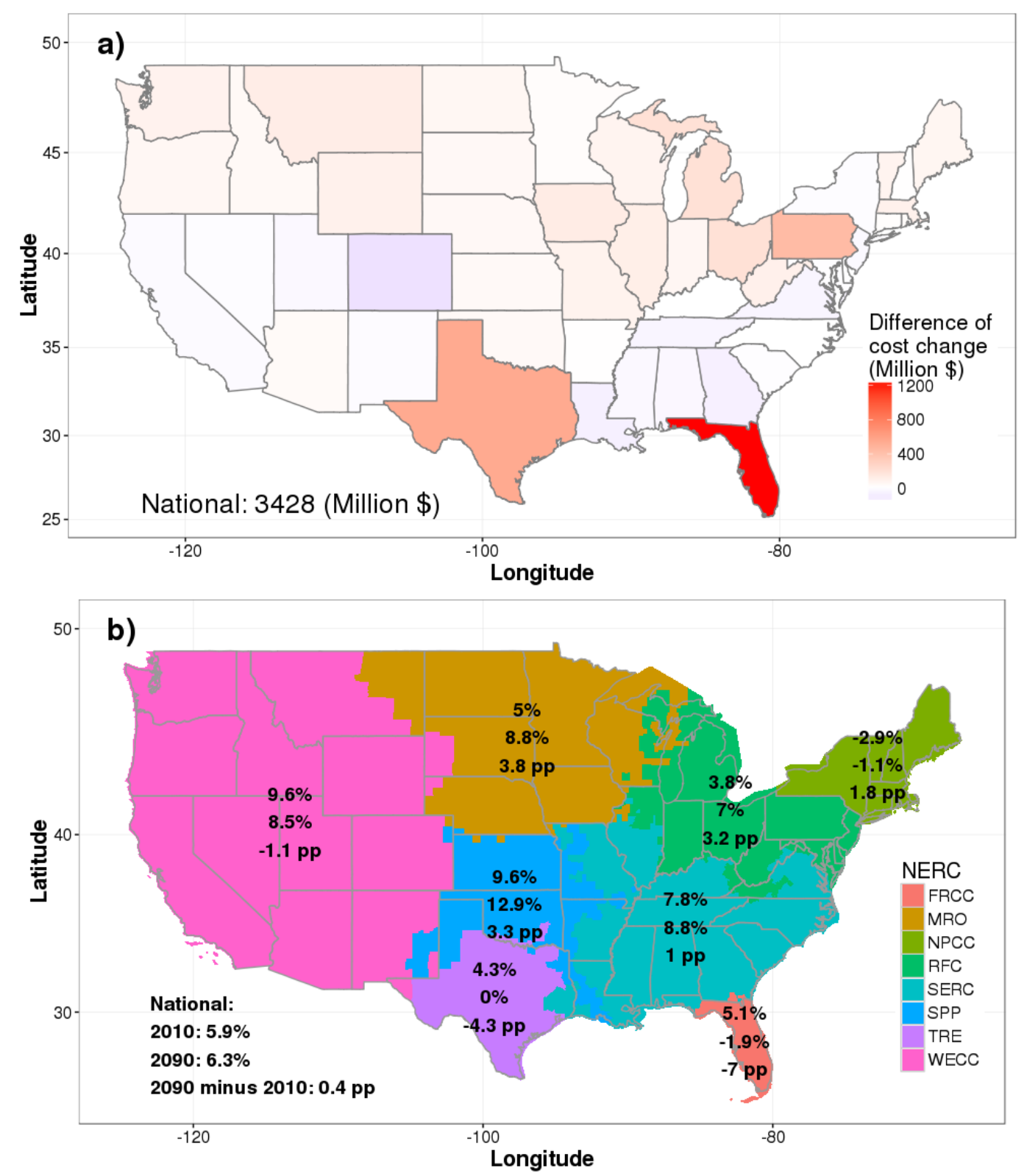

Figure 4. Sensitivity of consumer costs and reserve margins to population distribution in the 2080-99 time period. a) the difference of altered costs between the results using the 2090 versus the 2010 population distribution; b) the difference of altered reserve margins between the results using the 2090 versus 2010 population. The top, middle, and bottom numbers in b) represent the reserve margin (\%) based on 2010 population, the reserve margin (\%) based on 2090 population, and their difference (2090 minus 2010; unit: percentage point (pp)). 


\section{Conclusions}

Based on monthly energy demand changes driven by climate change in U.S. states, we evaluated the financial implications to energy consumers and suppliers. Increased energy costs were found in warmer states and decreased energy costs in colder states. The residential sector sees a savings about 7 billion $\$ /$ year for the whole U.S., while the commercial sector sees a net increase of 2.2 billion $\$ / y e a r$. At the state scale, changes in the average household annual residential energy costs range from -340 \$/household in Vermont to +231 \$ /household in Florida.

To meet the increased electricity demand needed in summer while simultaneously maintaining safe reserve margins, utilities will need to add capacity. In order to meet the $15 \%$ reserve margin requirement, $80.6 \mathrm{GW}$ of capacity is needed for the whole U.S., which amounts to $19.2-72.1$ billion $\$ /$ year in construction and operating costs. Were these costs passed to consumers, the net savings found in some states due to lowered heating needs, might be negated by electricity cost increases.

If a future scenario of U.S. population distribution is included, the impacts are further exacerbated in warmer regions and further diminished in colder regions. For example, the estimated change in annual building energy costs in Florida increases from $+\$ 2.7$ billion (based on 2010 population) to $+\$ 3.9$ billion (based on 2090 population), while the reserve margin is further reduced from $5.1 \%$ to $-1.9 \%$.

The estimated cost differences for consumers and suppliers explored here can provide insight into a number of challenges associated with quantifying and prioritizing climate policy. For example, the impact of climate change on building energy supply and demand at these space/time scales can provide a more accurate estimate of climate change damages and the social 
cost of carbon (Tol 2005). These costs, when combined with the analysis of climate change mitigation, can be further used to optimize the cost-benefit analysis and the pricing of carbon taxes (Roughgarden and Schneider 1999). Furthermore, the information presented here could offer a prioritization of climate change mitigation that is sensitive to varying costs and savings in different locations across the U.S. landscape.

Similar to previous research (Tol 2005), the work presented here is based on current socioeconomic conditions (e.g., population, economics, and policy). Hence, this should be viewed as a sensitivity study focusing on ceteris paribus analysis. Finally, given the complex relationship between energy consumers and suppliers, further research is required to better understand how the energy suppliers will pass the extra costs to consumers, and how consumer behavior will change in response to higher costs.

\section{Acknowledgements}

We would like to thank the National Science Foundation CAREER award 0846358, the Department of Energy grant \#DE-SC0006105 and Amazon cloud computing resources provided by Amazon Climate Research Grant Program.

\section{References}

Dirks J A, Gorrissen W J, Hathaway J H, Skorski D C, Scott M J, Pulsipher T C, Huang M, Liu Y and Rice J S 2015 Impacts of climate change on energy consumption and peak demand in buildings: A detailed regional approach Energy 79 20-32 Online: http://linkinghub.elsevier.com/retrieve/pii/S0360544214010469

Hadley S W, Erickson D J, Hernandez J L, Broniak C T and Blasing T J 2006 Responses of energy use to climate change: A climate modeling study Geophys. Res. Lett. 33

Hamlet A F, Lee S-Y, Mickelson K E B and Elsner M M 2010 Effects of projected climate change on energy supply and demand in the Pacific Northwest and Washington State Clim. 
Change 102 103-28

Huang J and Gurney K R 2016a Impact of climate change on U.S. building energy demand: sensitivity to spatiotemporal scales, balance point temperature, and population distribution Clim. Change 1-15 Online: http://dx.doi.org/10.1007/s10584-016-1681-6

Huang J and Gurney K R 2016b The variation of climate change impact on building energy consumption to building type and spatiotemporal scale Energy 111 137-53

Huang Y J 2006 The impact of climate change on the energy use of the US residential and commercial building sectors Lawrence Berkeley Natl. Lab. Rep. No. LBNL-60754

Isaac M and Van Vuuren D P 2009 Modeling global residential sector energy demand for heating and air conditioning in the context of climate change Energy Policy 37 507-21

Jaglom W S, McFarland J R, Colley M F, Mack C B, Venkatesh B, Miller R L, Haydel J, Schultz P a., Perkins B, Casola J H, Martinich J a., Cross P, Kolian M J and Kayin S 2014 Assessment of projected temperature impacts from climate change on the U.S. electric power sector using the Integrated Planning Model® Energy Policy 73 524-39 Online: http://dx.doi.org/10.1016/j.enpol.2014.04.032

Kelso J 20122011 Buildings Energy Data Book. Available at: http://buildingsdatabook.eren.doe.gov/

Linder K P and Inglis M R 1989 The potential impact of climate change on electric utilities, regional and national estimates US Environ. Prot. Agency, Washington, DC

Mansur E T, Mendelsohn R and Morrison W 2008 Climate change adaptation: A study of fuel choice and consumption in the US energy sector J. Environ. Econ. Manage. 55 175-93

McFarland J, Zhou Y, Clarke L, Sullivan P, Colman J, Jaglom W S, Colley M, Patel P, Eom J, Kim S H, Kyle G P, Schultz P, Venkatesh B, Haydel J, Mack C and Creason J 2015 Impacts of rising air temperatures and emissions mitigation on electricity demand and supply in the United States: a multi-model comparison Clim. Change 111-25 Online: http://link.springer.com/10.1007/s10584-015-1380-8

Mendelsohn R, Morrison W, Schlesinger M E and Andronova N G 2000 Country-specific market impacts of climate change Clim. Change 45 553-69

Nastasi B and Basso G L 2016 Hydrogen to link heat and electricity in the transition towards future Smart Energy Systems Energy 110 5-22

North American Electric Reliability Corporation: http://www.nerc.com/AboutNERC/keyplayers/Pages/Regional-Entities.aspx

North American Electric Reliability Corporation (2008-2010). Summer Reliability Assessment. Available at: http://www.nerc.com/pa/RAPA/ra/Pages/default.aspx

Rosenthal D H, Gruenspecht H K and Moran E A 1995 Effects of global warming on energy use for space heating and cooling in the United States Energy J. 77-96

Roughgarden T and Schneider S H 1999 Climate change policy: Quantifying uncertainties for damages and optimal carbon taxes Energy Policy 27 415-29

Ruth M and Lin A-C 2006 Regional energy demand and adaptations to climate change: methodology and application to the state of Maryland, USA Energy Policy 34 2820-33 
Sailor D J 2001 Relating residential and commercial sector electricity loads to climateevaluating state level sensitivities and vulnerabilities Energy 26 645-57

Sailor D J and Muñoz J R 1997 Sensitivity of electricity and natural gas consumption to climate in the USA - methodology and results for eight states Energy 22 987-98

Sailor D J, Rosen J N and Muñoz J R 1998 Natural gas consumption and climate: a comprehensive set of predictive state-level models for the United States Energy 39265 Online: http://linkinghub.elsevier.com/retrieve/pii/S0140670198963895

Sathaye J a., Dale L L, Larsen P H, Fitts G a., Koy K, Lewis S M and de Lucena A F P 2013 Estimating impacts of warming temperatures on California's electricity system Glob. Environ. Chang. 23 499-511 Online: http://linkinghub.elsevier.com/retrieve/pii/S0959378012001458

Scott M J, Wrench L E and Hadley D L 1994 Effects of climate change on commercial building energy demand Energy sources 16 317-32

Tol R S J 2005 The marginal damage costs of carbon dioxide emissions: an assessment of the uncertainties Energy Policy 33 2064-74

U.S. Census Bureau 2008-2012 American Community Survey 5-year estimates. Available at: http://www.census.gov/acs/www/data_documentation/2012_release/.

U.S. Energy Information Administration Levelized Cost and Levelized Avoided Cost of New Generation Resources in the Annual Energy Outlook 2014

U.S. Energy Information Administration State Energy Data System. Available here: http://www.eia.gov/state/seds/

U.S. Energy Information Administration 2016 Annual Energy Outlook. Available here: http://www.eia.gov/outlooks/aeo/U.S. Environmental Protection Agency 2012 Emissions \& Generation Resource Integrated Database (eGRID). Available at: http://www.epa.gov/cleanenergy/energy-resources/egrid/index.html.

U.S. Environmental Protection Agency 2010 ICLUS Tools and Datasets (Version 1.3 \& 1.3.1). U.S. Environmental Protection Agency, Washington, DC, EPA/600/R-09/143F

van Vuuren D P, Edmonds J, Kainuma M, Riahi K, Thomson A, Hibbard K, Hurtt G C, Kram T, Krey V, Lamarque J F, Masui T, Meinshausen M, Nakicenovic N, Smith S J and Rose S K 2011 The representative concentration pathways: An overview Clim. Change 109 5-31

Wang H and Chen Q 2014 Impact of climate change heating and cooling energy use in buildings in the United States Energy Build. 82 428-36 Online: http://linkinghub.elsevier.com/retrieve/pii/S0378778814005726

Xu P, Huang Y J, Miller N, Schlegel N and Shen P 2012 Impacts of climate change on building heating and cooling energy patterns in California Energy 44 792-804

Zhou Y, Clarke L, Eom J, Kyle P, Patel P, Kim S H, Dirks J, Jensen E, Liu Y, Rice J and others 2014 Modeling the effect of climate change on US state-level buildings energy demands in an integrated assessment framework Appl. Energy 113 1077-88

Zhou Y, Eom J and Clarke L 2013 The effect of global climate change, population distribution, and climate mitigation on building energy use in the US and China Clim. Change 119 97992 